\title{
Effect of Water flow Rate on the Yield Strength of a Reinforced bar Vincent Musonda ${ }^{1,} \mathrm{a}^{*}$, Esther Akinlabi ${ }^{1}$, Tien-Chien Jen ${ }^{1}$ \\ ${ }^{1}$ Department of Mechanical Engineering Science, University of Johannesburg, Auckland Park Kingsway Campus, Johannesburg, South Africa, 2006. \\ amusondachandi@gmail.com
}

\section{Keywords: Hot rolling, Microstructure, Rebar, TMT, Water flow rate, Yield Strength}

\begin{abstract}
High strength requirement of Thermo-mechanically treated (TMT) rebars is crucial in the construction of flyovers, bridges and high rise buildings because of the good combination of the mechanical properties. The yield strength is expected to be between $450 \mathrm{MPa}$ and $550 \mathrm{MPa}$ after the hot rolling process depending on prescribed standards. A series of experimental trials during a hot rolling process were carried out in a steel plant in which parameters such as the water flow rate and the processing time were varied to study their effect on the evolving mechanical properties of the rebars. Four "heats"(A "heat" is a batch of molten steel, referred to as tap to tap cycle and involves furnace charging with scrap, melting, deslagging, tapping molten steel and furnace turn-around. Furnace turn-around is the period following completion of tapping until the furnace is recharged for the next "heat") were done to produce Y $12 \mathrm{~mm}$ reinforced bars (rebars). For every "heat" done, tensile tests were carried out on the samples every after 15 minutes to establish the yield strength of the rebar. At least eight samples were tested in every "heat". It was observed that some samples showed low values of yield strength $(<450 \mathrm{MPa})$ which falls short of the minimum guaranteed yield strength. It was further noted that the water flow rate in the water cooling chamber was far below $600 \mathrm{~m}^{3} / \mathrm{h}$ for this size of rebar in some cases. A series of these tests were conducted and the water flow rate adjusted in order to arrive at the optimum flow rate corresponding to the expected yield strength and microstructure. The quenching time in the water cooling chamber was in the range 0.1 to 0.5 seconds and the results obtained both for the tensile tests and microstructure after several adjustments to the flow rate in particular yielded optimum results consistent with prescribed standards.
\end{abstract}

\section{Introduction}

Concrete reinforcing bars (rebars) are not only key products to the construction industries but also high quality rebars are essential to the consumers who are concerned about the desired mechanical properties [1, 2]. The rebars are generally produced from scrap melted in an Electric Arc Furnace (EAF) at a temperature of about $1600^{\circ} \mathrm{C}$. Refining is carried out in a ladle furnace. Casting is performed in billet casters and the billets are sent to the roughing mill and hot rolled for initial austenite decomposition. Though the strength of rebar can be increased by the addition of various alloying elements, there is a risk of reducing the ductility, weldability and the bendability of the finished product if this strengthening route is not controlled [3, 4].

There are, however, various options and parameters used to control and produce quality steel bars and TMT is one such route. After the finishing stand of the hot rolling schedule, the red heated rebar is passed through a chamber with controlled water flow and superficially quenched for less than one second $(<1 \mathrm{sec})$ resulting in rapid cooling of the surface area of the rebar. However, the inside or core of the rebar remains red heated at this stage. The water flow in the range of 600 to $800 \mathrm{~m}^{3} / \mathrm{h}$ is introduced, depending on the diameter of the bar being processed, at a pressure in the order of 1.2 MPa [2]. After the finishing stand, the quenched rebar is exposed to air cooling at the cooling bed where the quenched surface gets auto tempered due to the heat flow from high temperature core to low temperature surface. Finally, in the cooling bed, the austenitic core becomes transformed into ferrite and pearlite [2]. Fig. 1 shows the cross-section of TMT rebar just 
after water quenching and subsequent final cooling [3].

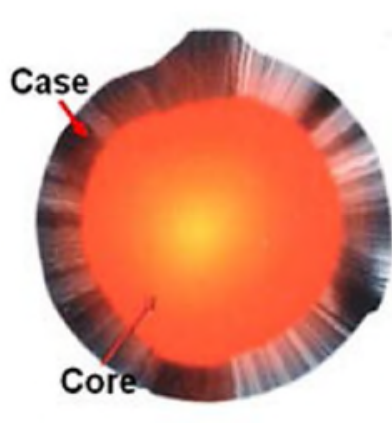

(a)

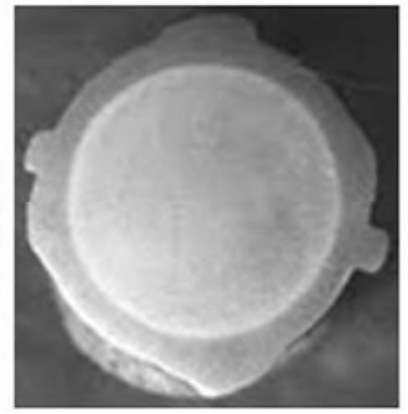

(b)

Fig. 1 Cross-section of TMT rebar just after (a) water quenching and (b) after final cooling [3].

Achieving the desired mechanical properties requires maintaining the tempering temperature sufficiently within a predetermined range. The length of the quenching line and the cooling water flow rate are the obvious control variables because they are easy to adjust during rolling and they have a strong effect on the yield strength of the rebars [1]. Depending on chemical compositions of the hot rolled rebar, cooling parameters might be adjusted for optimization of the mechanical properties of the rebars. However, there are possible problems encountered in TMT of rebars. These would either be that: the quenching rate is relatively low or the rolled rebar was in the water cooling chamber for a relatively longer period of time [3]. In all these scenarios, the transition zone of steel is highly affected and this usually results in larger area of transition zone of steel. It should also be pointed out that imbalanced cooling will result in insufficient inner heat of the rebar not tempering the martensite case properly. The case area will be either very soft or hard. For soft case, the steel will not provide optimum design strength and for very hard case the steel will not provide optimum ductility which might cause brittle type of failure [3].

Control of the cooling rate of the surface area of rebar is very important. As a standard practice, the surface temperature should be cooled to below $200{ }^{\circ} \mathrm{C}$ at the cooling bed and this should be done within few seconds [3]. In the absence of online temperature tracking, a pyrometer or an Infrared Thermometer (IR) can be used to monitor this temperature at the cooling bed. The temperature at the cooling bed eventually settles to room temperature. It is at the cooling bed where mechanical properties of rebar is finalised to obtain the desired fine grain sized ferrite.

\section{Chemical Composition}

The chemical composition of the alloying elements of rebar is shown in table 1 below. In order to know the combined effect of the alloying elements of rebars, their carbon equivalent (CE) values were calculated using the equation (1) below [5].

Table 1. Chemical composition of the alloying elements of rebar.

\begin{tabular}{|l|l|l|l|l|l|l|l|l|l|l|}
\hline$\% \mathrm{C}$ & $\% \mathrm{Mn}$ & $\% \mathrm{Si}$ & $\% \mathrm{~S}$ & $\% \mathrm{P}$ & $\% \mathrm{Cr}$ & $\% \mathrm{Ni}$ & $\% \mathrm{Mo}$ & $\% \mathrm{Al}$ & $\% \mathrm{Cu}$ & $\% \mathrm{~V}$ \\
\hline 0.24 & 0.65 & 0.08 & 0.020 & 0.035 & 0.23 & 0.12 & 0.02 & - & 0.30 & 0.082 \\
\hline
\end{tabular}

The Carbon Equivalent (CE) value is given by;

$\% \mathrm{CE}=\mathrm{C}+\frac{\mathrm{Mn}}{6}+\frac{\mathrm{Cr}+\mathrm{Mo}+\mathrm{V}}{5}+\frac{\mathrm{Ni}+\mathrm{Cu}}{15} \approx 0.44 \%$

$0.44 \%$ is an acceptable value of Carbon equivalent in the samples. 


\section{Data Collected and Results}

Table 2. Tensile Test Report (To Rodmill).

\begin{tabular}{|c|c|c|c|c|}
\hline \multicolumn{5}{|c|}{$\begin{array}{l}\text { SIZE: Y } 12 \mathrm{~mm} \\
\text { Heat Number: A }\end{array}$} \\
\hline Sample No. & $\begin{array}{c}\text { Water flow rate } \\
\qquad\left(\mathrm{m}^{3} / \mathrm{h}\right)\end{array}$ & $\begin{array}{l}\text { Yield Strength } \\
(\mathrm{MPa})\end{array}$ & $\begin{array}{l}\text { U.T.S } \\
\text { (MPa) }\end{array}$ & $\%$ Elongation \\
\hline 1 & 619 & 482.89 & 589.25 & 23.33 \\
\hline 2 & 619 & 532.10 & 611.52 & 21.07 \\
\hline 3 & 620 & 525.90 & 618.26 & 20.00 \\
\hline 4 & 620 & 475.85 & 581.22 & 21.64 \\
\hline 5 & 645 & 511.15 & 605.86 & 20.00 \\
\hline 6 & 645 & 512.13 & 605.55 & 18.33 \\
\hline 7 & 645 & 512.47 & 605.80 & 21.67 \\
\hline 8 & 645 & 482.05 & 580.28 & 23.33 \\
\hline
\end{tabular}

$\leadsto$ Water flow rate - -Yield Strength $(\mathrm{MPa}) \multimap$ U.T.S $(\mathrm{MPa}) \longleftarrow \%$ Elongation

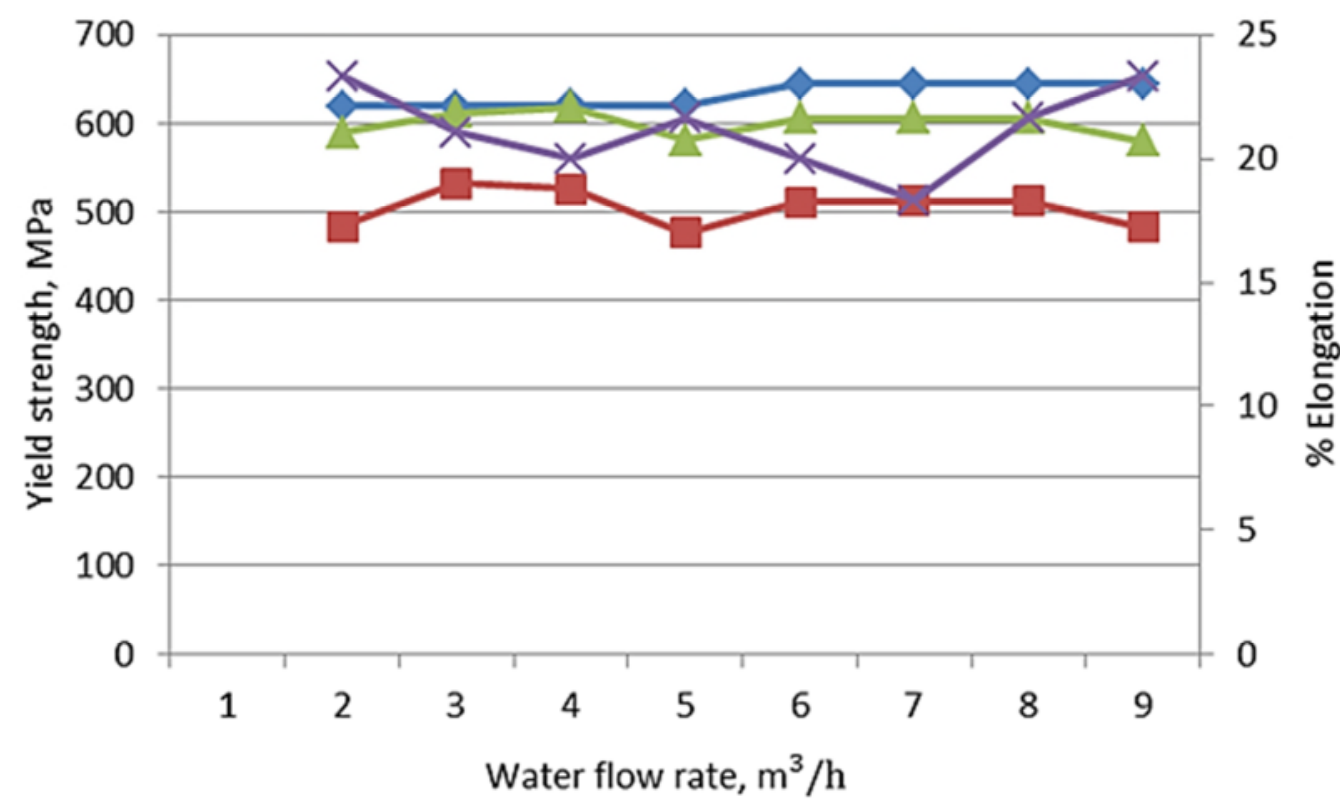

Fig. 2 Effect of water flow rate on Yield Strength. 


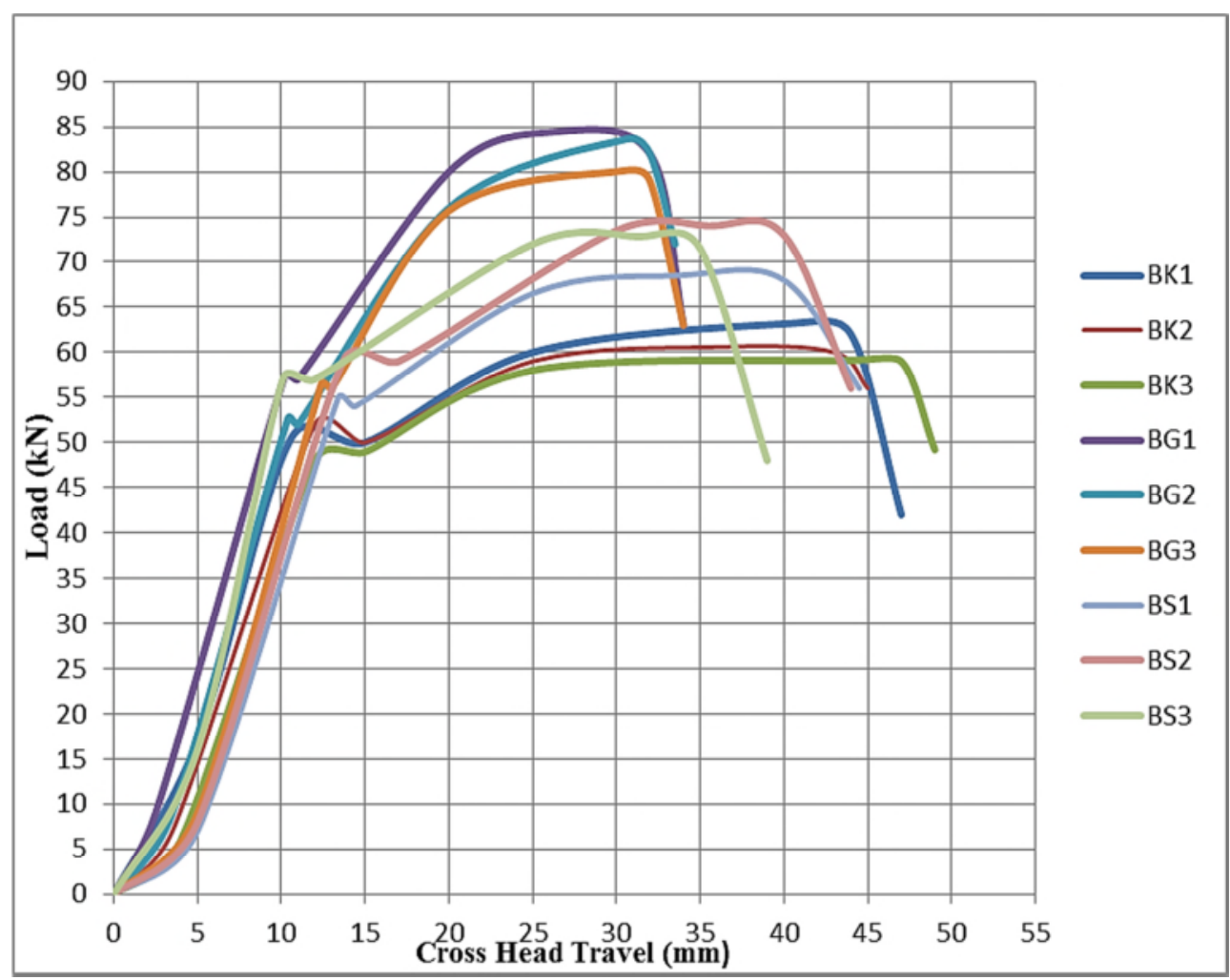

Fig. 3 Y 12 rebar Load Extension graph of different "Heat" samples.

\section{Microstructural Observations}

The microstructure of the core zone for Y12 rebar is shown in Fig. 4 (a) to (c):

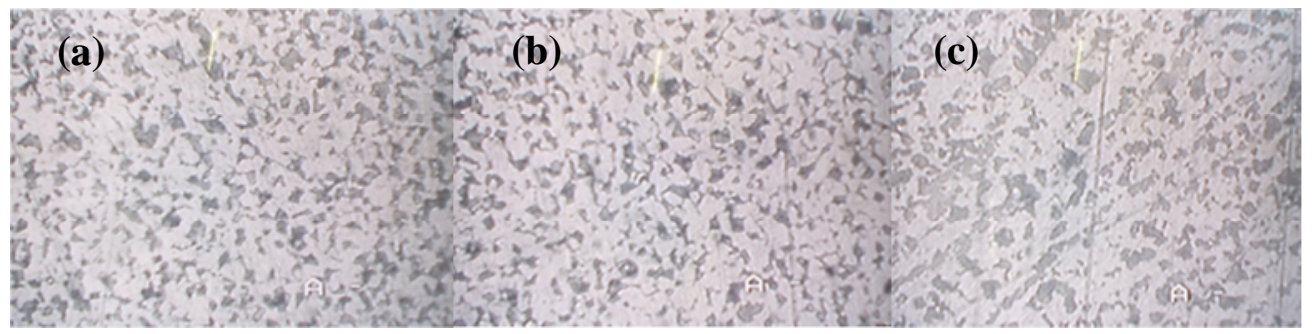

Fig. 4. Optical micrographs showing the core areas of rebar at X200, (a) Transverse section, (b) Transverse section (c) Longitudinal section. In all cases -pearlite (dark), ferrite (white).

\section{Discussion and Conclusions}

This paper has shown that the cooling water flow rate has an effect on the yield stress of a rebar. Fig. 2 shows that when water flow is not sufficient, the yield stress will be lower than the minimum guaranteed yield strength of $450 \mathrm{MPa}$. After several adjustments to the flow rate, the flow stabilised from 619 to $645 \mathrm{~m}^{3} / \mathrm{h}$ (Heat Number: A). For Heat number B not in the report, the flow remained constant at $669 \mathrm{~m}^{3} / \mathrm{h}$. Fig. 2, clearly shows that with correctly adjusted flow rate, the yield stress remained stable and maintained between $482 \mathrm{MPa}$ to $530 \mathrm{MPa}$. These values are acceptable according to the Zambia Bureau of Standards (ZABS: ZS 433:2005) and South African Bureau of Standards (SABS: SANS 920:2011). According to these standards, the yield stress should be between $450 \mathrm{MPa}$ and $550 \mathrm{MPa}$. Any product that is not within this threshold is rejected and sent back to the steel making processing line. For Ultimate Tensile Strength (UTS), the maximum is 650 $\mathrm{MPa}$. The average percentage elongation in this investigation was approximately $21 \%$ which is well above the minimum 14\% according to the standards. The microstructure of the specimens in Fig. 4 also indicates that austenite decomposed to pearlite and ferrite. The ultimate in hot rolling process is to achieve the fine small grain size of ferrite upon complete recrystallization. This was achieved and 
this is demonstrated by the dominance of the white patches of ferrite in the microstructure. The load extension graph in Fig. 3 also shows the variations in the yield points and fracture during and after the adjustments to the water flow rate.

\section{Acknowledgement}

This research work was made possible by the Kafue Steel Plant at Universal Mining and Chemical Industries limited (UMCIL) in Zambia. We sincerely thank the entire management and workshop staff members and in particular Dr Julius Kaoma, for their unconditional support and Ms Kaliyekha Nyirenda for assistance with the laboratory work.

\section{References}

[1] P. Simon, M. Economopoulos and P. Nillies, TEMPCORE, an economical process for the production of high quality rebars", reprint from MPT-Metallurgical Plant and Technology, 3(84) (2017) 80-93.

[2] J. Madias, M. Wright, and P. Wolkowicz, Reinforcing Bar: Hardening Mechanisms and Performance in Use, Conference: AISTech 2016 proceedings, (2017), pp. 2287-2296.

[3] I. R. Kabir, M. A. Islam, Hardened Case Properties and Tensile Behaviours of TMT Steel Bars, American J. Mech. Eng. 2(1) (2014) 8-14.

[4] B. K. Panigrahi, S. Srikanth, G. Sahoo, Effect of alloying Elements on Tensile Properties, Microstructure and Corrosion Resistance of Reinforcing Bar Steel, J. Mat. Eng. Perfom. ASM Int. 18 (2009) 1102-1108.

[5] South Africa Bureau of Standards (SABS Standards SANS 920:2011) and Zambia Bureau of Standards ZS 433: 2005. 